\title{
Wacker-oxidation of Ethylene over Pillared Layered Material Catalysts
}

\author{
Róbert Barthos ${ }^{*}$, András Hegyessy, Zoltán May, József Valyon \\ Institute of Materials and Environmental Chemistry, Research Centre for Natural Sciences, \\ Hungarian Academy of Sciences, Pusztaszeri út 59-67, Budapest 1025, Hungary \\ *Corresponding author. Tel:+36 1 4381130; fax:+36 14381164 \\ E-mail addresses: barthos.robert@ttk.mta.hu (Róbert Barthos), hegyessy@gmail.com (András \\ Hegyessy), may.zoltan@ttk.mta.hu (Zoltán May), valyon.jozsef@ttk.mta.hu (József Valyon)
}

\begin{abstract}
This paper concerns the Wacker oxidation of ethylene by oxygen in the presence of water over supported $\mathrm{Pd} / \mathrm{VO}_{\mathrm{x}}$ catalysts. High surface area porous supports were obtained from layer-structured materials, such as, montmorillonite (MT), laponite (LT) (smectites), and hydrotalcite (layered double hydroxide, $\mathrm{LDH}$ ) by pillaring. Before introduction of $\mathrm{Pd}$, supports MT and LDH were pillared by vanadia. The laponite was used in titania-pillared form $\left(\mathrm{TiO}_{2}\right.$-LAP) as support of $\mathrm{Pd} / \mathrm{VO}_{\mathrm{x}}$ active component. Acetaldehyde $(\mathrm{AcH})$, acetic acid $(\mathrm{AcOH})$ and $\mathrm{CO}_{2}$ were the products with yields and selectivities, depending on the reaction conditions and the properties of the applied catalyst. Under comparable conditions the pillared smectite catalysts gave higher AcH yield than the pillared LDH catalyst. UV-vis spectroscopic examination suggested that the pillared smectites contained polymeric chains of $\mathrm{VO}_{4}$, whereas only isolated monomeric $\mathrm{VO}_{4}$ species were present in the pillared $\mathrm{LDH}$. The higher catalytic activity in the Wacker oxidation was attributed to the more favorable redox property of the polymeric than of the monomeric vanadia. The $\mathrm{V}^{3+}$ ions in the polymeric species can reduce $\mathrm{O}_{2}$ to $\mathrm{O}^{2-}$ ions, whereas the obtained $\mathrm{V}^{5+}$ ions are ready to pass over $\mathrm{O}$ to $\mathrm{Pd}^{0}$ to generate $\mathrm{PdO}$ whereon the oxidation of the ethylene proceeds.
\end{abstract}

Keywords: Wacker oxidation $\cdot$ Supported $\mathrm{Pd} / \mathrm{VO}_{\mathrm{x}}$ catalyst $\cdot$ Pillared layered materials $\cdot \mathrm{UV}$ VIS spectroscopy $\mathrm{H}_{2}$-TPR

\section{Introduction}

Acetaldehyde is a commodity chemical. By the end of the last century the world's production of acetaldehyde attained 2.9 million tons/year. About $85 \%$ of this amount was 
manufactured in plants exploiting the method, patented by the Wacker and Hoechst companies in 1959. The process involves bubbling mixture of ethylene and oxygen (air) through aqueous solution of homogeneous catalyst consisting of $\mathrm{HCl}, \mathrm{PdCl}_{2}$ and $\mathrm{CuCl}_{2}$. In the first step of the reaction $\mathrm{Pd}^{2+}$ cations promote the nucleophyllic attack of alkene by water, the ethylene takes up an oxygen atom, and the $\mathrm{Pd}^{2+}$ gets reduced to $\mathrm{Pd}^{0}$. The role of co-catalyst $\mathrm{Cu}^{2+}$ ions is to selectively re-oxidize the $\mathrm{Pd}^{0}$ to $\mathrm{Pd}^{2+}$. The catalytic cycle is closed by the reoxidation of the resulting $\mathrm{Cu}^{+}$by $\mathrm{O}_{2}$ [1]. However, the liquid-phase homogeneous process has many disadvantages, such as the high corrosivity of $\mathrm{HCl}$ in the presence of oxygen, possible formation of undesired chlorinated by-products, difficult recovery of the products from solution, loss of palladium, etc. A solid catalyst that functions like the homogeneous catalytic system could overcome most of these drawbacks [2].

There have been a number of attempts to heterogenize the homogeneous Wacker catalyst system by binding an active complex onto a carrier material and, thereby, combine the advantages of the homogeneous and heterogeneous catalysts. Various oxides $\left(\mathrm{Al}_{2} \mathrm{O}_{3}, \mathrm{SiO}_{2}\right.$, $\mathrm{TiO}_{2}$ ) [3-6] and carbon[7,8] were used as support. In these systems either vanadia [3-5] or copper [67-8] was the co-catalyst of palladium. Espeel et al.[9] used $\mathrm{Cu}-\mathrm{Pd}$ exchanged $\mathrm{Y}$ zeolites to initiate selective AcH formation in the reaction of ethylene and oxygen. Terminal oxidation of alpha olefins was attained using Pd-MT catalyst in acid-free aqueous solution of $\mathrm{CuCl}_{2}$ and $\mathrm{N}, \mathrm{N}$-dimethylacetamide [10]. Porous glass was used by Arhancet [11] to adsorb palladium and copper salts and generate, thereby, a heterogenized Wacker-system. Recently active palladium/copper chloride composition, fixed to silica-supported liquid polymer medium, was used to make $\mathrm{AcH}$ by selective vapor phase oxidation of ethylene 12].

With the objective of mitigating some engineering problems of the Wacker reaction a membrane reactor was developed by Frusteri et al. [13]. A Pd or Pt/carbon membrane was applied to separate an oxidizing liquid phase and a gas flow containing the reactant ethylene. The reaction was accompanied by a continuous countercurrant transport of the reactant and the products through the catalytically active membrane.

The present study shows that active heterogeneous Wacker type catalyst can be prepared by depositing Pd on vanadia-pillared layered materials, such as, smectites and LDH.

\section{Experimental}

\subsection{Preparation of catalysts}


Smectite layers comprise of two tetrahedral $\mathrm{SiO}_{4}$ sheets sandwiching an octahedral $\mathrm{AlO}_{4}$ sheet. Substitution of some $\mathrm{Al}^{3+}$ to $\mathrm{Mg}^{2+}$ or $\mathrm{Li}^{+}$raises a negative charge on the layers, compensated by hydrated cations in the interlayer region. The interlayer ions can be exchanged by $\mathrm{VO}^{2+}$ cations [14]. When the ion exchanged samples are subject of careful thermal treatment dehydration and dehydroxylation occur and highly dispersed $\mathrm{V}_{2} \mathrm{O}_{5}$ particles are formed, which keep the layers apart like pillars.

As a first step of making vanadia-pillared montmorillonite $\left(\mathrm{VO}_{\mathrm{x}}-\mathrm{MT}\right) 10 \mathrm{~g}$ of montmorillonite K-10 (Aldrich) was suspended in $1000 \mathrm{~cm}^{3}$ distilled water at $50{ }^{\circ} \mathrm{C}$ by intense stirring of the mixture for $4 \mathrm{~h}$. Then, $500 \mathrm{~cm}^{3}$ solution, having a vanadyl sulfate (Sigma-Aldrich, $97 \%$ purity) concentration of $0.02 \mathrm{~mol} / \mathrm{dm}^{3}$, was added to the stirred suspension dropwise. The amount of added $\mathrm{VOSO}_{4}(10 \mathrm{mmol})$ was near to equivalent with the ion exchange capacity(IEC) of the used MT (12 mmol/10 g). After additional 16-hour stirring at $50{ }^{\circ} \mathrm{C}$ the suspension was filtered, the obtained solid was washed with distilled water, and dried in air at $120^{\circ} \mathrm{C}$ overnight. The dried material was calcined at $400{ }^{\circ} \mathrm{C}$ for $4 \mathrm{~h}$. The chemical analysis of the sample showed that $37 \%$ of the vanadium moved from the exchange solution into the MT structure. This amount corresponds to about $30 \%$ of the IEC of the MT.

The laponite (LT) is synthetic structural analogue of hectorite. The LT sample (XLG, Rockwood Ltd.) was pillared twice: first with titania $\left(\mathrm{TiO}_{2}-\mathrm{LT}\right)$ and then with vanadia $\left(\mathrm{VO}_{\mathrm{x}}-\mathrm{TiO}_{2}-\mathrm{LT}\right)$ as described by Long et al. [14]. The Ti was introduced from an aqueous solution, containing $\mathrm{TiCl}_{4}$ and $\mathrm{HCl}$ in concentrations of 0.94 and $0.66 \mathrm{~mol} / \mathrm{dm}^{3}$, respectively. Ten grams of LT was suspended in $1000 \mathrm{~cm}^{3}$ water and slowly $110 \mathrm{~cm}^{3}$ of the solution was added to it in drops. The amount of added $\mathrm{TiCl}_{4}(104 \mathrm{mmol})$ was about ten times as much as the ion exchange capacity of the used laponite $(10 \mathrm{mmol} / 10 \mathrm{~g})$. The particles separated from the liquid phase were dried at $120{ }^{\circ} \mathrm{C}$ overnight. The dried sample was calcined at $400{ }^{\circ} \mathrm{C}$ for $4 \mathrm{~h}$. The chemical analysis showed that close $90 \%$ of the added Ti $(90 \mathrm{mmol})$ remained in the solid in the form of titania.

The procedure, the treatments and the conditions of vanadia introduction in the $\mathrm{TiO}_{2}$-LT were similar to that described above for the MT sample. The amount of vanadium, moved from the $\mathrm{VOSO}_{4}$ solution into the $\mathrm{TiO}_{2}$-LT structure was about $37 \%$ of the total IEC of the LP sample.

The LDHs, known also as hydrotalcites, consist of brucite $\left[\mathrm{Mg}(\mathrm{OH})_{2}\right]$-like layers wherein a fraction of the divalent magnesium cations is substituted by trivalent ions. As a result, the layers get positive charge, which is balanced by hydrated anions in the interlayer space. The 
interlamellar ions can be exchanged by decavanadate, $\mathrm{V}_{10} \mathrm{O}_{28}{ }^{6-}$, anions. Thermal treatment of the ion-exchanged material must be applied to obtain the vanadia pillared hydrotalcite.

A $\mathrm{VO}_{\mathrm{x}}-\mathrm{LDH}$ sample was prepared following the receipt described by Wegrzyn et al.[15]. First $\mathrm{LDH}$ was made by mixing a $\mathrm{Mg}^{2+} / \mathrm{Al}^{3+}$ solution (2 to $1 \mathrm{Mg} / \mathrm{Al}$ molar ratio) and a solution containing $\mathrm{CO}_{3}{ }^{2-}$ ions at $60{ }^{\circ} \mathrm{C}$. Namely, $0.2 \mathrm{~mol}$ magnesium nitrate hexahydrate (99 $\%$ purity, Sigma-Aldrich) and $0.1 \mathrm{~mol}$ aluminium nitrate nonahydrate (98+\% purity, SigmaAldrich) was dissolved in $200 \mathrm{~cm}^{3}$ water and added in drops to $60 \mathrm{mmol}$ sodium carbonate, dissolved in $100 \mathrm{~cm}^{3}$ water. During addition of the nitrate solution the $\mathrm{pH}$ of the obtained slurry was kept at $10 \pm 0.2$ by gradual addition of $3.2 \mathrm{M} \mathrm{NaOH}$ solution. After having full amounts of the solutions combined the slurry was stirred at $60{ }^{\circ} \mathrm{C}$ for $1 \mathrm{~h}$. The interlayer carbonate anions were exchanged then by decavanadate $\left(\mathrm{V}_{10} \mathrm{O}_{28}{ }^{6-}\right)$ solution. The solution was made by dissolving $12.193 \mathrm{~g} \mathrm{NaVO}_{3}$ (Aldrich, 99.9\%) in $360 \mathrm{ml}$ water at $\mathrm{pH}=4.5$. The $\mathrm{pH}$ was adjusted using $1 \mathrm{M} \mathrm{HNO}_{3}$ solution. The ion-exchange was carried out at $\mathrm{pH}=4.5 \pm 0.1$ and was accomplished in $5 \mathrm{~min}$. Afterwards the suspension was filtered, washed by distilled water, dried at $110^{\circ} \mathrm{C}$ overnight and calcined then at $300{ }^{\circ} \mathrm{C}$ for 4 hours to get $\mathrm{VO}_{\mathrm{x}}-\mathrm{LDH}$ sample. The negative charge of the used decavanadate was near to equivalent with half of the ion-exchange capacity of the used LDH sample. The chemical analysis of the calcined sample showed that virtually the total vanadium content of the exchange solution became incorporated into the LDH structure.

Using $\mathrm{Pd}\left(\mathrm{NH}_{3}\right)_{4}\left(\mathrm{NO}_{3}\right)_{2}$ (Strem Chemicals Inc.) a solution was made containing $5 \mathrm{wt} \% \mathrm{Pd}$. Catalysts of about 0.6-0.8 wt\% Pd content were obtained by impregnating the above described supported vanadia preparations with the solution and calcining them at $300{ }^{\circ} \mathrm{C}\left(\mathrm{VO}_{\mathrm{x}}-\mathrm{LDH}\right)$ or $400{ }^{\circ} \mathrm{C}\left(\mathrm{VO}_{\mathrm{x}}-\mathrm{MT}\right.$ and $\left.\mathrm{VO}_{\mathrm{x}}-\mathrm{TiO}_{2}-\mathrm{LT}\right)$ for 4 hours. The catalysts were designated as $\mathrm{Pd} / \mathrm{VO}_{\mathrm{x}^{-}}$ MT, $\mathrm{Pd} / \mathrm{VO}_{\mathrm{x}-}-\mathrm{TiO}_{2}-\mathrm{LT}$, and $\mathrm{Pd} / \mathrm{VO}_{\mathrm{x}}-\mathrm{LDH}$.

\subsection{Characterization}

A Philips PW 1810/3710 X-ray diffractometer, applying monochromatized $\mathrm{CuK}_{\alpha}$ radiation $(40 \mathrm{kV}, 35 \mathrm{~mA}$ ) was used. The XRD patterns of the samples (Fig. 1) were recorded at ambient conditions collecting data between $3^{\circ}$ and $65^{\circ} 2 \Theta$ degrees in $0.02^{\circ}$ steps for $0.5 \mathrm{~s}$ at each step.

Nitrogen physisorption measurements were carried out at $-195{ }^{\circ} \mathrm{C}$ using Quantachrome NOVA Automated Gas Sorption Instrument. Prior to measurements the samples were outgassed at $150{ }^{\circ} \mathrm{C}$ for $8 \mathrm{~h}$. The specific surface area (SSA) values were calculated by the BET method from seven measured points of the $\mathrm{N}_{2}$ adsorption isotherm recorded in the relative pressure interval from 0.05 to 0.35 at $-195{ }^{\circ} \mathrm{C}$ (Table 1 . 
The morphology of the preparations (Fig. 2) was examined by Morgagni 268D Transmission Electron Microscope $(100 \mathrm{kV}$, W filament, point resolution $=0.5 \mathrm{~nm})$

The palladium and vanadium content of samples (Table 1) was determined by means of ICP-OES sequential plasma emission spectrometer with radial plasma viewing (Thermo Jarrell Ash, AtomScan 25 type).

Temperature-programmed reduction measurements were carried out by hydrogen $\left(\mathrm{H}_{2}-\right.$ TPR) using a flow-through microreactor (I.D. $4 \mathrm{~mm}$ ) made of quartz. About $100 \mathrm{mg}$ of catalyst sample (particle size: $0.25-0.5 \mathrm{~mm}$ ) was placed into the microreactor and was pre-treated in a $30 \mathrm{~cm}^{3} / \mathrm{min}$ flow of $\mathrm{O}_{2}$ at $350{ }^{\circ} \mathrm{C}$ for $1 \mathrm{~h}$ before the measurement. The pre-treated sample was cooled to room temperature in the $\mathrm{O}_{2}$ flow, flushed by $\mathrm{N}_{2}$ at room temperature for $30 \mathrm{~min}$ then was contacted with a $30 \mathrm{~cm}^{3} / \mathrm{min}$ flow of $10 \% \mathrm{H}_{2} / \mathrm{N}_{2}$ mixture. The reactor temperature was ramped up at a rate of $10{ }^{\circ} \mathrm{C} / \mathrm{min}$ to $600{ }^{\circ} \mathrm{C}$ and held at this temperature for $1 \mathrm{~h}$, while the effluent gas was passed through a liquid nitrogen trap and a thermal conductivity detector (TCD). Data were collected and processed by computer. Calculation of the corresponding hydrogen consumptions based on the peak areas was carried out by using the calibration value determined with the $\mathrm{H}_{2}$-TPR of $\mathrm{CuO}$ reference material. The reducibility of the catalysts was characterized by the molar hydrogen consumption of the $\mathrm{PdO}$ and the $\mathrm{VO}_{\mathrm{x}}$ phases. The $\mathrm{VO}_{\mathrm{x}}$ reducibility of the $\mathrm{VO}_{\mathrm{x}}-\mathrm{MT}$ and $\mathrm{VO}_{\mathrm{x}}-\mathrm{TiO}_{2}-\mathrm{LT}$ samples were obtained by correcting the total hydrogen consumption of the samples with the hydrogen consumption of the MT and $\mathrm{TiO}_{2}$-LT support, respectively, determined in separate TPR experiments. Similar correction was applied to obtain the extent of palladium reduction in the $\mathrm{Pd} / \mathrm{MT}$ and $\mathrm{Pd} / \mathrm{TiO}_{2}$-LT samples. In order to obtain the extent of $\mathrm{VO}_{\mathrm{x}}$ reduction in the $\mathrm{Pd} / \mathrm{VO}_{\mathrm{x}}-\mathrm{MT}$ and $\mathrm{Pd} / \mathrm{VO}_{\mathrm{x}}-\mathrm{TiO}_{2}-\mathrm{LT}$ catalysts the $\mathrm{H}_{2}$ consumptions obtained for the $\mathrm{Pd} / \mathrm{MT}$ and $\mathrm{Pd} / \mathrm{TiO}_{2}$-LT samples was taken in correction (Fig. 3 and Table 2).

A tapered element oscillating microbalance (TEOM 1500 Pulse Mass Analyzer from Rupprecht \& Patashnick Co.) was used to determine the CO chemisorption of the pre-reduced Pd-containing catalysts. About $100 \mathrm{mg}$ of catalyst sample was reduced in flowing $\mathrm{H}_{2}$ at $300{ }^{\circ} \mathrm{C}\left(\mathrm{Pd} / \mathrm{VO}_{\mathrm{x}}-\mathrm{LDH}\right)$ or $400{ }^{\circ} \mathrm{C}\left(\mathrm{Pd} / \mathrm{VO}_{\mathrm{x}}-\mathrm{TiO}_{2}-\mathrm{LT}\right.$; $\left.\mathrm{Pd} / \mathrm{VO}_{\mathrm{x}}-\mathrm{MT}\right)$, flushed by $\mathrm{He}$ at the reduction temperature for $60 \mathrm{~min}$ then cooled to $40^{\circ} \mathrm{C}$. After having a stabilized weight monitored for about for $3 \mathrm{~h}$, the sample was contacted with a flow of $3 \% \mathrm{CO} / \mathrm{He}$ for $60 \mathrm{~min}$ at $40^{\circ} \mathrm{C}$ followed by a repeated flushing with $\mathrm{He}$ for $60 \mathrm{~min}$ at the same temperature. The chemisorbed amount of $\mathrm{CO}$ was determined as difference of the weights recorded in He flow before after contacting the catalyst with $\mathrm{CO}$. 
UV-vis spectra of the preparations were collected by Thermo Scientific Evolution 300 UV-VIS spectrophotometer equipped with Praying Mantis Diffuse Reflectance Accessory and High Temperature and Pressure Reaction Chamber, allowing in situ measurements of powdered solids (in situ DR-UV-vis). The reference materials $\left(\mathrm{NaVO}_{3}, 99.9 \%, \mathrm{Na}_{3} \mathrm{VO}_{4}\right.$ 99.98\%, Sigma-Aldrich products) and all the studied preparations were finely ground and diluted with $\mathrm{BaSO}_{4}$ (Alfa Aesar, Puratronic 99,998\%). The DR-UV-vis spectra were measured against $\mathrm{BaSO}_{4}$ as background. The dilution was applied to get Kubelka-Munk function $\mathrm{F}(\mathrm{R} \infty)$ $<1$. In order to obtain spectra of dehydrated samples both the background and absorbance data were collected at $350{ }^{\circ} \mathrm{C}$ after in-situ calcination at $350{ }^{\circ} \mathrm{C}$ in flowing oxygen for $30 \mathrm{~min}$. The edge energy $\left(E_{g}\right)$ for allowed transitions were obtained as the intercept of the straight line fitted to the low-energy rise of the $[F(R \infty) \times h v]^{2}$ vs. hv plot (Fig. 4) as described in refs. $[16,17]$.

\subsection{Catalytic activity measurements}

The catalyst preparations were characterized by their activity and selectivity in the Wacker oxidation of ethylene (Fig 5). In the reaction $500 \mathrm{mg}$ of catalyst sample (particle size 0.85 $1.70 \mathrm{~mm}$ ) was used at atmospheric pressure in a fixed-bed continuous flow glass tube reactor, having an internal diameter of $4 \mathrm{~mm}$. The catalyst was activated in situ in the reactor in oxygen flow $\left(20 \mathrm{~cm}^{3} / \mathrm{min}\right)$ at $350^{\circ} \mathrm{C}$ for $1 \mathrm{~h}$ then contacted with a gas flow of $3 \% \mathrm{C}_{2} \mathrm{H}_{4} / 12 \%$ $\mathrm{O}_{2} / 24 \% \mathrm{H}_{2} \mathrm{O} / \mathrm{He}$ at a total flow rate of $30 \mathrm{~cm}^{3} / \mathrm{min}$. The reactor effluent was analyzed by an on-line Shimadzu GC-2010 gas chromatograph equipped with automatic gas sampling valve and 30-m long HP-PLOT-U column. On each temperature the reaction was followed for 5 hours. Flame-ionization detector (FID) was used to detect the main organic compounds, such as $\mathrm{C}_{2} \mathrm{H}_{4}, \mathrm{AcH}, \mathrm{AcOH}$, and the minor organic by-products, if any, whereas thermal conductivity detector (TCD) was applied to get signal from $\mathrm{O}_{2}, \mathrm{CO}_{2}$ and water. Between the reactor outlet and the GC the temperature of the gas line and the sampling valve was maintained at $120{ }^{\circ} \mathrm{C}$ in order to avoid the condensation of water and reaction products. The GC was calibrated for each reactant and product separately. The conversion of ethylene was calculated from the ethylene concentrations of the feed and the reactor effluent. The selectivities were calculated on the basis of the carbon content of the products. For instance, the acetaldehyde selectivity $(\mathrm{S})$ was obtained as $\mathrm{S}_{\mathrm{AcH}}=2 \mathrm{c}_{\mathrm{AcH}} /\left(2 \mathrm{c}_{\mathrm{AcH}}+2 \mathrm{c}_{\mathrm{AcOH}}+\mathrm{c}_{\mathrm{CO}_{2}}\right)$.

\section{Results and discussion}


The XRD patterns of the layered materials and their pillared derivatives are shown in Fig. 1.

The LDH has a hexagonal type unit cell. The XRD reflections were indexed using the ICDD card $\mathrm{N}^{0} 35-0965$. The lattice parameters $c$ and $a$ were calculated from the position of the 003 and 110 reflections, respectively. For the parent $\mathrm{LDH}$ sample $\mathrm{c}=2.28 \mathrm{~nm}$ and $\mathrm{a}=3.04$ $\mathrm{nm}$ was obtained. After incorporation of vanadia species the 003, 006, and 009 reflections shifted to lower $2 \Theta$ values. Thus, the intercalation of decavanadate anions in the LDH brought about an increase in the interlayer distance from 0.76 to $0.98 \mathrm{~nm}$. The position of 110 reflection did not change, indicating that the average cation-cation distance in the pillared octahedral, brucite-like sheets remained unaffected. The broad and weak reflections of the modified LDH sample indicate lattice disorder (Fig. 1A). Crystalline vanadia could not be detected despite of the relatively high vanadia content of the sample, suggesting high vanadia dispersion. Weak XRD lines belonging to hydrotalcite are also present after heat treatment at $300{ }^{\circ} \mathrm{C}\left(\mathrm{VO}_{\mathrm{x}}-\mathrm{LDH}(\mathrm{a})\right)$. As Labajos et al. [18] demonstrated that distorted LDH structure is present after heat treatment at $275{ }^{\circ} \mathrm{C}$, whereas appearance of $\mathrm{MgO}$ and $\mathrm{Mg}$ - $\mathrm{Al}$-spinel structures were indicated only after treatment at $500{ }^{\circ} \mathrm{C}$ and above. The structural damage of our LDH sample is more pronounced, probably due to the affect of the acidic medium applied for ion exchange by $\mathrm{V}_{10} \mathrm{O}_{56}{ }^{6-}$ ions. Heat treatment increased structural disorder but the LDH lines of the heat treated sample are still detectable (Fig. 1, see $\mathrm{VO}_{\mathrm{x}}-\mathrm{LDH}(\mathrm{a})$ ).

In accordance with the finding of Long et al. [14] the introduction of vanadia in between the layers of the MT sample did not alter its XRD pattern (Fig. 1B). No vanadia reflections could be discerned. These findings may infer that calcination could not convert significant amount of the $\mathrm{VO}^{+}$cations to $\mathrm{VO}_{\mathrm{x}}$ species, alternatively, the $\mathrm{VO}_{\mathrm{x}}$, if formed, is present on the outer surface of the MT sample in highly dispersed form.

The strong acidic medium applied in the process of the titania-pillaring delaminated the LT sample as suggested by the much weaker LT reflections of the $\mathrm{TiO}_{2}$-LT sample than those of the original LT sample (Fig. 1C). The weakening of the reflections is stronger than that explained by the presence of $39 \mathrm{wt} \%$ titania beside the LT phase. The weak XRD peaks of LT are accompanied by strong anatase reflections (ICDD Card No. 21-1272).

The SSA of the vanadia-containing sample was regularly smaller than the SSA of the corresponding support material having layered structure (Table 1). In contrast, the titaniapillared LT sample had a higher SSA than the LT phase alone. This finding suggests that delamination of the laponite phase occurred during the pillaring procedure. However, the 
conversion of the $\mathrm{TiO}_{2}-\mathrm{LT}$ to $\mathrm{VO}_{\mathrm{x}}-\mathrm{TiO}_{2}-\mathrm{LT}$ by $\mathrm{VO}^{2+}$ cation exchange and subsequent calcination reduced the surface area as it happened with the other samples (Table 1).

No reflections of $\mathrm{PdO}$ or $\mathrm{Pd}^{0}$ were found on the XRD patterns of the calcined catalysts, i. e., the XRD patterns of the $\mathrm{VO}_{\mathrm{x}}$ and $\mathrm{Pd} / \mathrm{VO}_{\mathrm{x}}$ preparations were the same. The TEM images of the catalysts are shown in Fig. 2. The pillaring process and the palladium introduction did not significantly alter the morphology of the parent layered materials (not shown). Appearance of palladium metal particles was not expected and particles were not discerned since catalysts were not pre-reduced before the TEM examination.

According to present knowledge [19] the oxidation of the alkene proceeds with cooperation of $\mathrm{V}_{2} \mathrm{O}_{5}, \mathrm{PdO}$ and $\mathrm{H}_{2} \mathrm{O}$. In latter reaction $\mathrm{AcH}, \mathrm{AcOH}, \mathrm{CO}_{2}$ products, $\mathrm{Pd}^{0}$ and, most probably, $\mathrm{V}^{4+}$ is obtained. The alkene oxidation is accomplished in an oxygen transfer chain. The catalytic cycle proceeds if $\mathrm{O}_{2}$ gas re-oxidizes the vanadium co-catalyst. The rate of any oxygen transfer step can determine the rate of oxidation reaction. If the oxidation/reduction rate of the vanadia was slow it could limit the rate of the Wacker oxidation reaction. The reducibility of supported $\mathrm{VO}_{\mathrm{x}}$ and $\mathrm{Pd} / \mathrm{VO}_{\mathrm{x}}$ samples by hydrogen was used to characterize the oxygen/electron donor ability of the vanadia phase. Fig. 3 shows $\mathrm{H}_{2}$-TPR profiles. The $\mathrm{H}_{2}$ consumptions, calculated by integration of the $\mathrm{H}_{2}$-TPR peaks, are given Table 2. The hydrogen consumption of the MT support $(253 \mu \mathrm{mol} / \mathrm{g})$ is much higher than that of the $\mathrm{TiO}_{2^{-}}$ LT support $(89 \mu \mathrm{mol} / \mathrm{g})$. Unlike the LT, the MT, being of natural origin, contains reducible transition metal ions in an amount close to $2 \mathrm{wt} \%$. The main component is iron (1.86 wt \%). The palladium in the catalyst preparation increased the complexity of the reduction pattern. The reduction of palladium occurs at relatively low temperature $\left(<\sim 100{ }^{\circ} \mathrm{C}\right)$ where the generated $\mathrm{Pd}^{0}$ particles adsorb hydrogen that is released at a somewhat higher but still at relatively low temperature (Fig. 3). Discern the small negative peaks on the TPR curves of the Pd-containing MT preparations below about $100{ }^{\circ} \mathrm{C}$, indicating $\mathrm{H}_{2}$ desorption from the palladium that must have been reduced in contact with hydrogen before the programmed temperature raise was started (Fig. 3B). The reduction of palladium over the LT containing preparations are somewhat hindered giving a sharp peak at about $100{ }^{\circ} \mathrm{C}$. The reduced palladium can activate $\mathrm{H}_{2}$ for the reduction of other reducible components shifting their reduction peaks to lower temperatures. This effect is more pronounced on the $\mathrm{Pd} / \mathrm{MT}$ sample containing a significant amount of reducible transition metal than on the $\mathrm{Pd} / \mathrm{TiO}_{2}-\mathrm{LT}$ sample, containing only hard-to-reduce components like anatase and the pure synthetic smectite LT. The difference of the $\mathrm{H}_{2}$ consumption of the $\mathrm{Pd} / \mathrm{MT}$ and MT preparations was calculated. Because the palladium enhances reducibility (and became reduced before the experiment was 
started) the difference in the $\mathrm{H}_{2}$ consumption of the two materials probably reflects the affect of palladium on the reduction of metals in the MT support (Table 2). Similarly, the difference of the $\mathrm{H}_{2}$ consumption of the $\mathrm{Pd} / \mathrm{TiO}_{2}-\mathrm{LT}$ and $\mathrm{TiO}_{2}$-LT preparations was also determined. Considering the low reducibility of the $\mathrm{TiO}_{2}$-LT support, the difference allows the estimation of the $\mathrm{H}_{2} / \mathrm{Pd}$ value. A value of 0.47 was obtained in line with expectations. The TPR results suggest that vanadia is most difficult to reduce in the LDH preparations, although the presence of palladium promotes its reducibility.

It is well documented that vanadia catalysts are active in oxidative dehydrogenation reactions at about $450{ }^{\circ} \mathrm{C}$ where vanadia can participate in redox processes [20]. The $\mathrm{H}_{2}$-TPR results of the present work suggests that significant reduction of our supported $\mathrm{VO}_{\mathrm{x}}$ catalysts could be attained above $400{ }^{\circ} \mathrm{C}$. The reduction behavior of $\mathrm{VO}_{\mathrm{x}}-\mathrm{MT}$ and $\mathrm{VO}_{\mathrm{x}}-\mathrm{TiO}_{2}-\mathrm{LT}$ samples was similar although the temperature, whereon the reduction was started, and the temperature of maximum reduction rate were somewhat lower for the latter sample (513 vs. $563{ }^{\circ} \mathrm{C}$ ). In order to estimate the average oxidation state of the vanadium after the $\mathrm{H}_{2}-\mathrm{TPR}$ experiment the reducibility of the support was taken in correction assuming that the $\mathrm{H}_{2}$ consumption of the support was the same before and after vanadia introduction. Chemical analysis of the samples showed that the $\mathrm{VO}^{+}$ion exchange removed about $20 \%$ of the iron that was present in the native MT support. As a consequence the $\mathrm{H}_{2}$ consumption of the $\mathrm{VO}_{\mathrm{x}^{-}}$ MT sample was a bit over corrected, which led to a lower $\mathrm{H}_{2} / \mathrm{V}$ ratio $\left(\mathrm{H}_{2} / \mathrm{V}=0.62\right)$ than was the real value (Table 2). Because the support of the $\mathrm{VO}_{\mathrm{x}} / \mathrm{TiO}_{2}$-LT sample hardly contains ions which were both exchangeable and reducible the correction for the $\mathrm{H}_{2}$ uptake of the support is fairly applicable. The $\mathrm{H}_{2} / \mathrm{V}$ values suggest that the formal average oxidation state of vanadium must be over both supports between $\mathrm{V}^{3+}$ and $\mathrm{V}^{4+}$ at the end of the $\mathrm{H}_{2}$-TPR experiment (Table $2)$.

The DR UV-vis method is able to distinguish ortho and metavanadate compounds. The bulk orthovanadate $\left(\mathrm{Na}_{3} \mathrm{VO}_{4}\right)$ and metavanadate $\left(\mathrm{NaVO}_{3}\right)$ compounds contain isolated $\mathrm{VO}_{4}$ units and polymeric $\mathrm{VO}_{4}$ chains, respectively [17]. The edge energy $\left(\mathrm{E}_{\mathrm{g}}\right)$ of pure $\mathrm{NaVO}_{3}$ sample was found to be $2.98 \mathrm{eV}$ while that of $\mathrm{Na}_{3} \mathrm{VO}_{4}$ to $3.40 \mathrm{eV}$ (Fig. 4). The intermediate $\mathrm{E}_{\mathrm{g}}$ values of $\mathrm{NaVO}_{3} / \mathrm{Na}_{3} \mathrm{VO}_{4}$ mechanical mixtures showed linear dependence on the molar ratio. That means that after generating an $\mathrm{E}_{\mathrm{g}} \mathrm{vs}$. molar ratio calibration line the percentage of isolated and polymeric vanadia forms of the vanadia-containing catalysts can be obtained by determining the $\mathrm{E}_{\mathrm{g}}$ edge energy.

Fig. 4 shows that the $\mathrm{VO}_{\mathrm{x}}-\mathrm{LDH}$ sample contains virtually the same vanadia species as $\mathrm{Na}_{3} \mathrm{VO}_{4}$, i.e., isolated $\mathrm{VO}_{4}$ units $\left(\mathrm{E}_{\mathrm{g}}=3.38 \mathrm{eV}\right)$. In contrast, the $\mathrm{E}_{\mathrm{g}}$ values obtained for the 
$\mathrm{VO}_{\mathrm{x}}-\mathrm{MT}$ and $\mathrm{VO}_{\mathrm{x}}-\mathrm{TiO}_{2}-\mathrm{LT}$ samples were 3.22 and $3.16 \mathrm{eV}$, respectively, suggesting that these preparations contain mixtures of isolated $\mathrm{VO}_{4}$ units and polymeric $\mathrm{VO}_{4}$ chains. The redox properties of the vanadia component of the catalyst must have importance regarding the Wacker oxidation activity of the catalyst. The reducibility of vanadium atoms was found to depend on the polymerization level of vanadia [21]. The polymerized forms were shown to become more easily reduced than the isolated surface vanadia species. We can conclude that about 40 and $60 \%$ of vanadia are present in polymeric form in the $\mathrm{VO}_{\mathrm{x}}-\mathrm{MT}$ and $\mathrm{VO}_{\mathrm{x}}-\mathrm{TiO}_{2}-\mathrm{LT}$ samples, respectively. The $\mathrm{H}_{2}$-TPR showed that the MT and $\mathrm{TiO}_{2}-\mathrm{LT}$ supported $\mathrm{VO}_{\mathrm{x}}$ shows similar reducibility suggesting that the supports are of similar character or, regarding reducibility, the interaction between the support and the polymeric vanadia species is of secondary importance.

As expected, the palladium was found to have pronounced effect on the reducibility of the $\mathrm{VO}_{\mathrm{x}}$ in the supported $\mathrm{Pd} / \mathrm{VO}_{\mathrm{x}}$ catalysts. The $\mathrm{H}_{2}$-TPR pattern of the $\mathrm{Pd} / \mathrm{VO}_{\mathrm{x}}-\mathrm{TiO}_{2}-\mathrm{LT}$ catalyst shows one sharp peak at $84{ }^{\circ} \mathrm{C}$ and a broad peak between 180 and $600{ }^{\circ} \mathrm{C}$. In contrast, the $\mathrm{H}_{2-}$ TPR pattern of the $\mathrm{Pd} / \mathrm{VO}_{\mathrm{x}}-\mathrm{MT}$ catalyst exhibits peaks at 94,124 and $225^{\circ} \mathrm{C}$ sitting on the top of a broad peak overarching the whole temperature range of the measurement. In order to get the reduction degree of vanadium the hydrogen consumption of the corresponding Pdcontaining support was taken into correction. The average oxidation state of vanadium was between $\mathrm{V}^{2+}$ and $\mathrm{V}^{3+}$ in the $\mathrm{Pd} / \mathrm{VO}_{\mathrm{x}}-\mathrm{MT}$ catalyst whereas it was between $\mathrm{V}^{3+}$ and $\mathrm{V}^{4+}$ in the $\mathrm{Pd} / \mathrm{VO}_{\mathrm{x}}-\mathrm{TiO}_{2}-\mathrm{LT}$ catalyst. These results suggest that in presence of $\mathrm{Pd}$ the vanadia is more easily and deeply reducible on the MT than on the $\mathrm{TiO}_{2}$-LT support.

The results of catalytic test reactions are shown on Fig. 5. The main products, as expected, are $\mathrm{AcH}, \mathrm{AcOH}$ and $\mathrm{CO}_{2}$. Formation of methane and acetone was also detected with selectivities lower than about $1 \%$. Traces of propylene, acrolein and propionaldehyde were also discerned. It generally applies for all catalyst that, when the reaction temperature and conversion level is increased, the selectivity of $\mathrm{AcH}$ decreases, whereas the AcOH selectivity increases and the formation of $\mathrm{CO}_{2}$ rapidly grows. The $\mathrm{H}_{2}$-TPR curves show that the supported $\mathrm{Pd} / \mathrm{VO}_{\mathrm{x}}$ catalysts become partially reduced already at the low temperatures $\left(<200{ }^{\circ} \mathrm{C}\right)$ where the Wacker oxidation proceeds (Table 2). However, the oxidation state of the catalysts is significantly different. In the case of the MT supported catalyst the $\mathrm{H}_{2}$ consumption can be associated with the reduction of $\mathrm{V}^{5+}$ (the $\mathrm{PdO}$ must have been reduced at lower temperature, out of the range of the measurement), whereas in the case of the $\mathrm{TiO}_{2}$-LT supported catalyst virtually all the $\mathrm{H}_{2}$ consumption comes from the reduction of the $\mathrm{PdO}$ component. 
The reduction of the catalysts generates palladium particles on the support. The estimation of the average Pd particle size is generally determined by XRD using the Scherrer method or calculated from the dispersion, determined by $\mathrm{H}_{2}$ or $\mathrm{CO}$ chemisorptions measurement $[22,23]$. In the present study the $\mathrm{CO}$ chemisorptions method was used to obtain the dispersion of palladium particles over the catalysts reduced by $\mathrm{H}_{2}$ at $300{ }^{\circ} \mathrm{C}\left(\mathrm{Pd} / \mathrm{VO}_{\mathrm{x}}-\mathrm{LDH}\right)$ or $400{ }^{\circ} \mathrm{C}$ $\left(\mathrm{Pd} / \mathrm{VO}_{\mathrm{x}}-\mathrm{MT}, \mathrm{Pd} / \mathrm{VO}_{\mathrm{x}}-\mathrm{TiO}_{2}-\mathrm{LT}\right)$. It was assumed that the number of adsorbed $\mathrm{CO}$ molecules equals with the number of surface Pd atoms [22]. To calculate the particle diameter we used the $7.9 \times 10^{-2} \mathrm{~nm}^{2}$ value for the atomic surface area Pd and spherical particle model [22,23]. The obtained results are given in Table 1. Obviously support MT hinders less the aggregation of the reduced Pd atoms.

The Wacker oxidation proceeds in the presence of a reducing agent, the reactant ethylene, and the oxidizing agent $\mathrm{O}_{2}$ that is in excess to the amount needed for the stoichiometric total oxidation of ethylene. The $\mathrm{O}_{2}$ participates in a selective Wacker oxidation of ethylene to $\mathrm{AcH}$ and $\mathrm{AcOH}$ and in a non selective catalytic oxidation of the reactant and the organic products to $\mathrm{CO}_{2}$. The average valence state of the working catalyst is determined by the relative rates of these reactions that in turn strongly depend on the temperature. The $\mathrm{H}_{2}$-TPD results suggest that the oxide ions of the MT supported $\mathrm{Pd} / \mathrm{VO}_{\mathrm{x}}$ catalyst are more readily participate in redox processes that those of the $\mathrm{TiO}_{2}$-LT catalyst. That may have relation to the catalytic activity and selectivity in the Wacker oxidation of ethylene. The ethylene conversion and the oxidation to $\mathrm{CO}_{2}$ more rapidly increases with the increasing reaction temperature over the $\mathrm{Pd} / \mathrm{VO}_{\mathrm{x}}-\mathrm{TiO}_{2}-\mathrm{LT}$ catalyst than over $\mathrm{Pd} / \mathrm{VO}_{\mathrm{x}}-\mathrm{MT}$ suggesting that the activation of the $\mathrm{O}_{2}$ gas over the catalyst, having less mobile oxide ions, has a higher activation energy. As a consequence, the $\mathrm{AcH}$ selectivity rapidly drops as temperature is increased. Because of the opposite temperature dependence of conversion and $\mathrm{AcH}$ selectivity the $\mathrm{AcH}$ yield can be maximized by selecting the optimum reaction temperature.

The preparations, containing vanadia and no palladium, were not active in the oxidation of ethylene in the applied temperature range at all. When vanadium was absent the palladium on the support generated only carbon dioxide. These results prove that the Wacker mechanism, requiring both palladium and oxygen transfer co-catalyst, is effective in the partial oxidation of ethylene. The water is also important component of the process, however, if any oxidation proceeds water is formed. A minor amount of water in the reacting system could bring about the appearance of the Wacker products in minor amounts.

In spite of its highest vanadia content the lowest activity and $\mathrm{AcH}$ selectivity were obtained with the $\mathrm{Pd} / \mathrm{VO}_{\mathrm{x}}-\mathrm{LDH}$ catalyst. The XRD results (Fig. 1A and Fig. 2) showed that 
the original LDH structure was lost during vanadia introduction. The LDH framework is stable at $\mathrm{pH}>10$, but the intercalation of $\mathrm{V}_{10} \mathrm{O}_{56}{ }^{6-}$ had to be carried at $\mathrm{pH}=4.5$. Both the low $\mathrm{pH}$ and the dehydroxylation during calcination could result in the degradation of LDH layers. The eventual fractional occlusion of vanadia could hinder its intimate contact with palladium particles. Nevertheless, the appearance of AcH product showed a low Wacker-type selective oxidation activity of the catalyst. A further probable reason of the low activity is that this catalyst contains mainly isolated vanadia species of lower oxygen mobility than that attributed to the oxygen atoms of polymeric vanadia. The vanadia must act as electron transmitter. The electrons over polymeric vanadia chains are much more delocalized so this vanadia form can more easily transmit oxygen atoms from oxygen molecule than isolated vanadia species.

Since the iron and vanadium content of montmorilloite samples is in the same range, the Pd/MT (without vanadium) was also checked in separate catalytic test reaction. This composition proved to be inactive in Wacker oxidation of ethylene, although $\mathrm{Fe}^{3+} / \mathrm{Fe}^{2+}$ could serve as co-catalyst to $\mathrm{Pd}^{0} / \mathrm{Pd}^{2+}$, only formation of $\mathrm{CO}_{2}$ was observed.

Preliminary studies showed that nanosized anatase particles are favorable support for the vanadia/palladium redox ensembles for getting active Wacker catalyst. This infers that the enhanced catalytic activity of $\mathrm{Pd} / \mathrm{VO}_{\mathrm{x}}-\mathrm{TiO}_{2}-\mathrm{LT}$ is probably associated with presence of $\mathrm{TiO}_{2}$ nanoparticles. Further studies are needed to clarify the possible role of titania in the heterogeneous Wacker type selective oxidation catalysts.

\section{Conclusions}

It was attempted to introduce $\mathrm{VO}_{\mathrm{x}}$ species as pillars between the layers of $\mathrm{LDH}$ and smectites. The vanadia-modified materials were used as support for palladium. The selective catalytic partial ethylene oxidation was shown to follow the Wacker mechanism over all samples. The catalysts containing polymeric $\mathrm{VO}_{4}$ species were more active than the one containin monomeric $\mathrm{VO}_{4}$. The vanadia acts as electron transmitter. The electrons over polymeric vanadia chains are much more delocalized so this vanadia form can more easily transmit oxygen atoms from oxygen molecule than isolated vanadia species. The redox properties of the vanadia component were shown to be affected by the support-vanadia interaction and was significantly modified by the presence of palladium.

\section{Acknowledgement}

This work was financially supported by the Hungarian Scientific Research Fund (OTKA, contract no. K 100411). 
Table1. Characterization of the supports and catalysts.

\begin{tabular}{lll||lll}
\hline Sample ID $^{\mathbf{a}}$ & $\mathbf{S S A}, \mathbf{~ m}^{\mathbf{2}} / \mathbf{g}$ & $\mathbf{V}_{\mathbf{2}} \mathbf{O}_{\mathbf{5}}\left(\mathbf{T i O}_{\mathbf{2}}\right), \mathbf{w t} \%$ & $\mathbf{P d}, \mathbf{w t} \mathbf{w}^{\mathbf{b}}$ & $\mathbf{D ,} \mathbf{\%}^{\mathbf{c}}$ & $\mathbf{d}_{\mathbf{P d}}^{\mathbf{d}}, \mathbf{n m}$ \\
\hline $\mathrm{VO}_{\mathrm{x}}-\mathrm{LDH}(\mathrm{LDH})$ & $108(151)$ & 40.0 & 0.59 & 31 & 4 \\
$\mathrm{VO}_{\mathrm{x}}-\mathrm{MT}(\mathrm{MT})$ & $210(238)$ & 3.35 & 0.69 & 9 & 13 \\
$\mathrm{TiO}_{2}-\mathrm{LT}(\mathrm{LT})$ & $452(320)$ & - & & & \\
$\mathrm{VO}_{\mathrm{x}}-\mathrm{TiO}_{2}-\mathrm{LT}$ & 365 & $3.35(39.2)$ & 0.85 & 29 & 4
\end{tabular}

${ }^{\mathrm{a}} \mathrm{LDH}=$ Layered Double Hydroxide, MT=K-10 montmorillonite, LT=Laponite.

${ }^{\mathrm{b}}$ The amount of Pd introduced in the vanadia-pillared sample. The SSA of each Pd catalyst was about the same as that of its support.

${ }^{\mathrm{c}} \mathrm{Pd}$-dispersity of the reduced catalyst. Calculated from $\mathrm{CO}$ chemsorption capacity. The number of the surface Pd atoms was taken as equal with the number of adsorbed $\mathrm{CO}$ molecules.

${ }^{d}$ The diameter of Pd particles was calculated with an area of $0.079 \mathrm{~nm}^{2} / \mathrm{Pd}$ atom

Table2. Results derived from the H-TPR measurements of Fig. 3.

\begin{tabular}{|c|c|c|}
\hline Sample ID & $\mathrm{H}_{2}\left(\mu \mathrm{mol} / \mathrm{g}_{\mathrm{cat}}\right)$ & $\mathrm{H}_{2} / \mathrm{V}\left(\mathrm{H}_{2} / \mathrm{Pd}\right)$ \\
\hline MT & 253 & - \\
\hline $\mathrm{Pd} / \mathrm{MT}$ & 309 & $0.81^{\mathrm{a}}$ \\
\hline $\mathrm{VO}_{\mathrm{x}}-\mathrm{MT}$ & 484 & $>0.62$ \\
\hline $\mathrm{Pd} / \mathrm{VO}_{\mathrm{x}}-\mathrm{MT}$ & $781\left(253^{b}+528^{c}\right)$ & 1.28 \\
\hline $\mathrm{TiO}_{2}-\mathrm{LT}$ & 89 & - \\
\hline $\mathrm{Pd} / \mathrm{TiO}_{2}-\mathrm{LT}$ & $129\left(45^{\mathrm{b}}+84^{\mathrm{c}}\right)$ & $(0.47)$ \\
\hline $\mathrm{VO}_{\mathrm{x}}-\mathrm{TiO}_{2}-\mathrm{LT}$ & 384 & 0.80 \\
\hline $\mathrm{Pd} / \mathrm{VO}_{\mathrm{x}}-\mathrm{TiO}_{2}-\mathrm{LT}$ & $429\left(139^{b}+290^{c}\right)$ & 0.81 \\
\hline $\mathrm{Pd} / \mathrm{LDH}$ & 97 & - \\
\hline $\mathrm{VO}_{\mathrm{x}}-\mathrm{LDH}$ & 2046 & 0.83 \\
\hline $\mathrm{Pd} / \mathrm{VO}_{\mathrm{x}}-\mathrm{LDH}$ & 2275 & 0.92 \\
\hline
\end{tabular}

${ }^{a}$ The difference of the $\mathrm{H}_{2}$ consumption of $\mathrm{Pd} / \mathrm{MT}$ and MT devided by the molar vanadium content. The number showes the Pd-induced reducibility increase of the MT support.

${ }^{\mathrm{b}} \mathrm{H}_{2}$ uptake up to $200{ }^{\circ} \mathrm{C}$.

${ }^{\mathrm{c}} \mathrm{H}_{2}$ uptake from $200{ }^{\circ} \mathrm{C}$ up. 

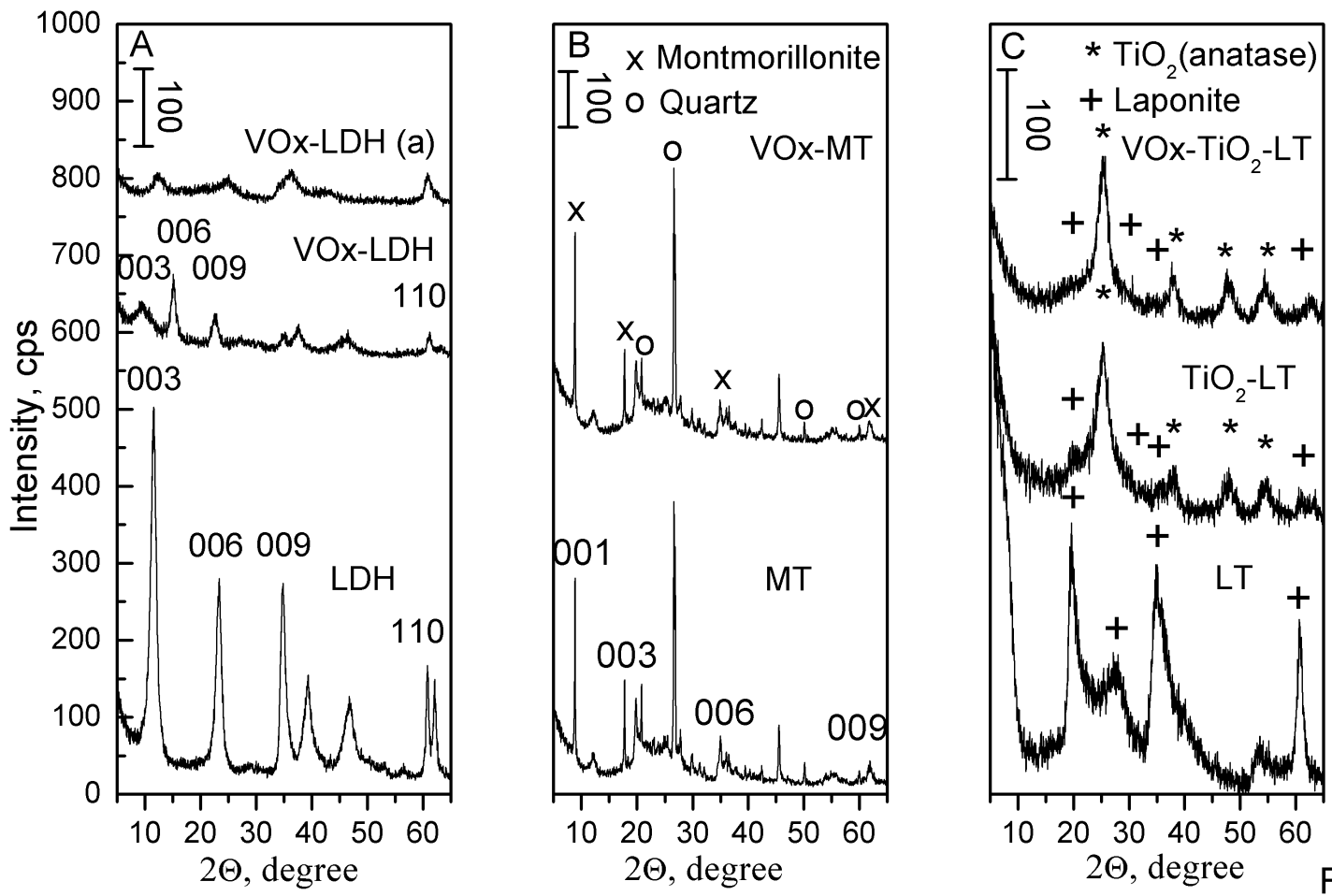

Fig. 1. XRD patterns of layered and pillared layered materials recorded at room temperature. Section A shows the diffractogram of the $\mathrm{LDH}$ and $\mathrm{VO}_{\mathrm{x}}-\mathrm{LDH}$ sample after drying at $110^{\circ} \mathrm{C}$ overnight and the diffractogram of the $\mathrm{VO}_{\mathrm{x}}-\mathrm{LDH}(\mathrm{a})$ sample, obtained from the $\mathrm{VO}_{\mathrm{x}}-\mathrm{LDH}$ sample by heating it in air at $300{ }^{\circ} \mathrm{C}$ for $4 \mathrm{~h}$. The diffractograms in sections $\mathrm{B}$ and $\mathrm{C}$ were recorded for samples activated in air at $400{ }^{\circ} \mathrm{C}$ for $3 \mathrm{~h}$. 

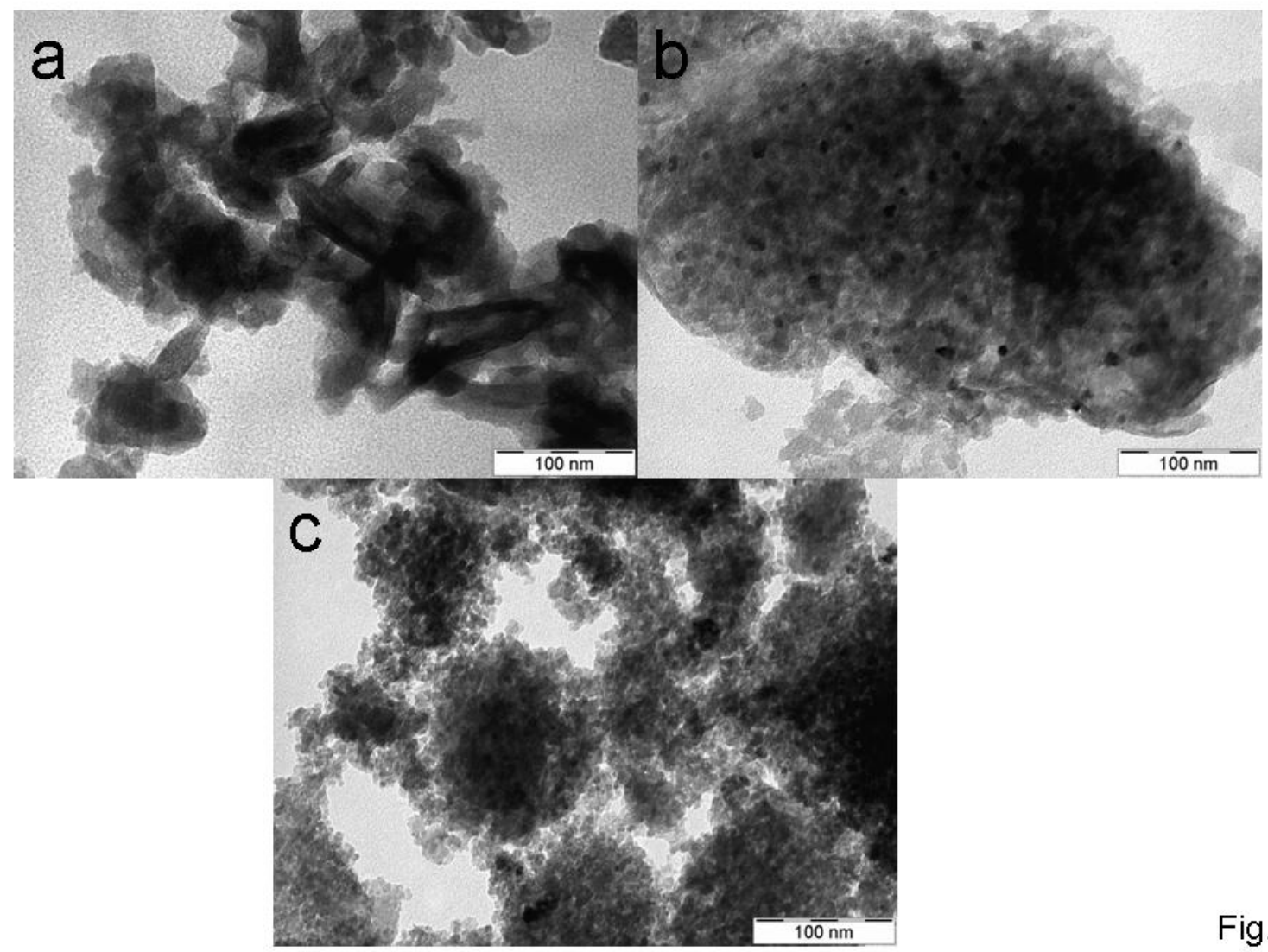

Fig. 2.

Fig. 2. TEM images of a) $\mathrm{Pd} / \mathrm{VOx}-\mathrm{LDH}$, b) $\mathrm{Pd} / \mathrm{VOx}-\mathrm{MT}$, c) $\mathrm{Pd} / \mathrm{VOx}-\mathrm{TiO}_{2}-\mathrm{LT}$. The $\mathrm{LDH}$ and the other catalysts were pre-calcined in air at $300^{\circ} \mathrm{C}$ and $400{ }^{\circ} \mathrm{C}$, respectively. 


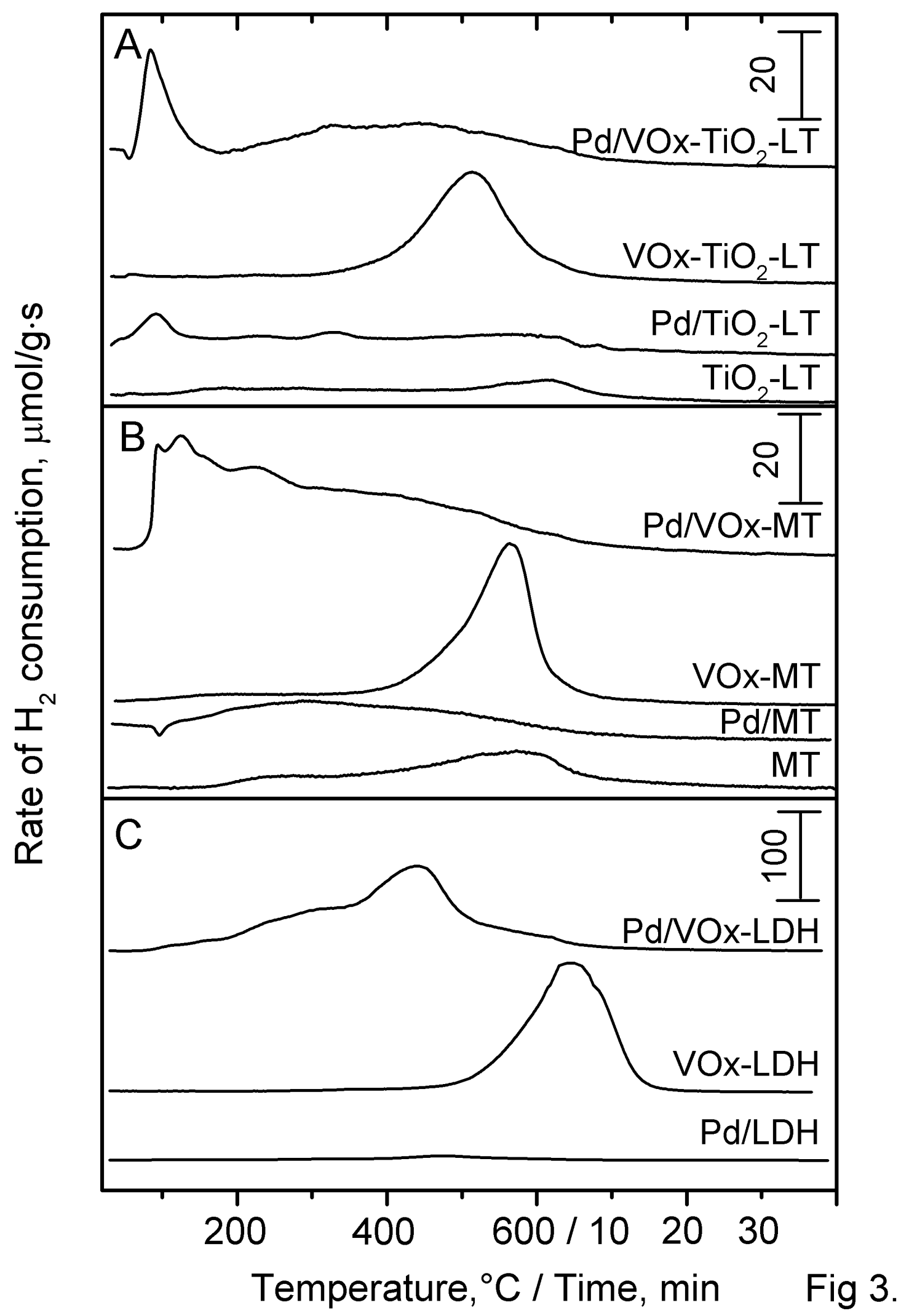

Fig. 3. $\mathrm{H}_{2}-\mathrm{TPR}$ profiles of catalyst precursors and catalyst samples 


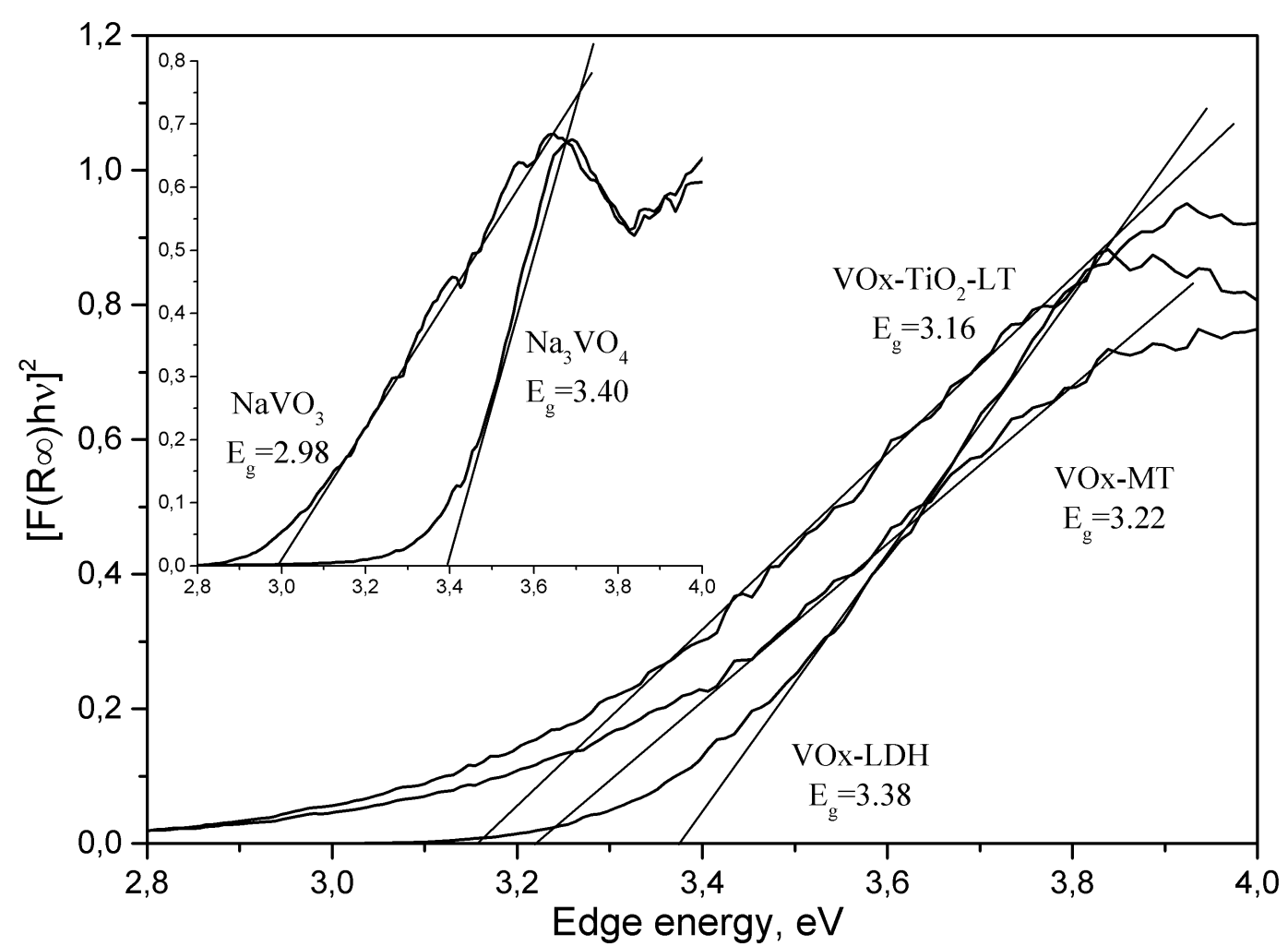

Fig. 4

Fig. 4. UV-vis DR spectra and $E_{g}$ values of reference (insert) and catalyst materials. Both the background and absorbance data were collected at $350{ }^{\circ} \mathrm{C}$ after in-situ calcination at $350{ }^{\circ} \mathrm{C}$ in flowing oxygen for $30 \mathrm{~min}$. 

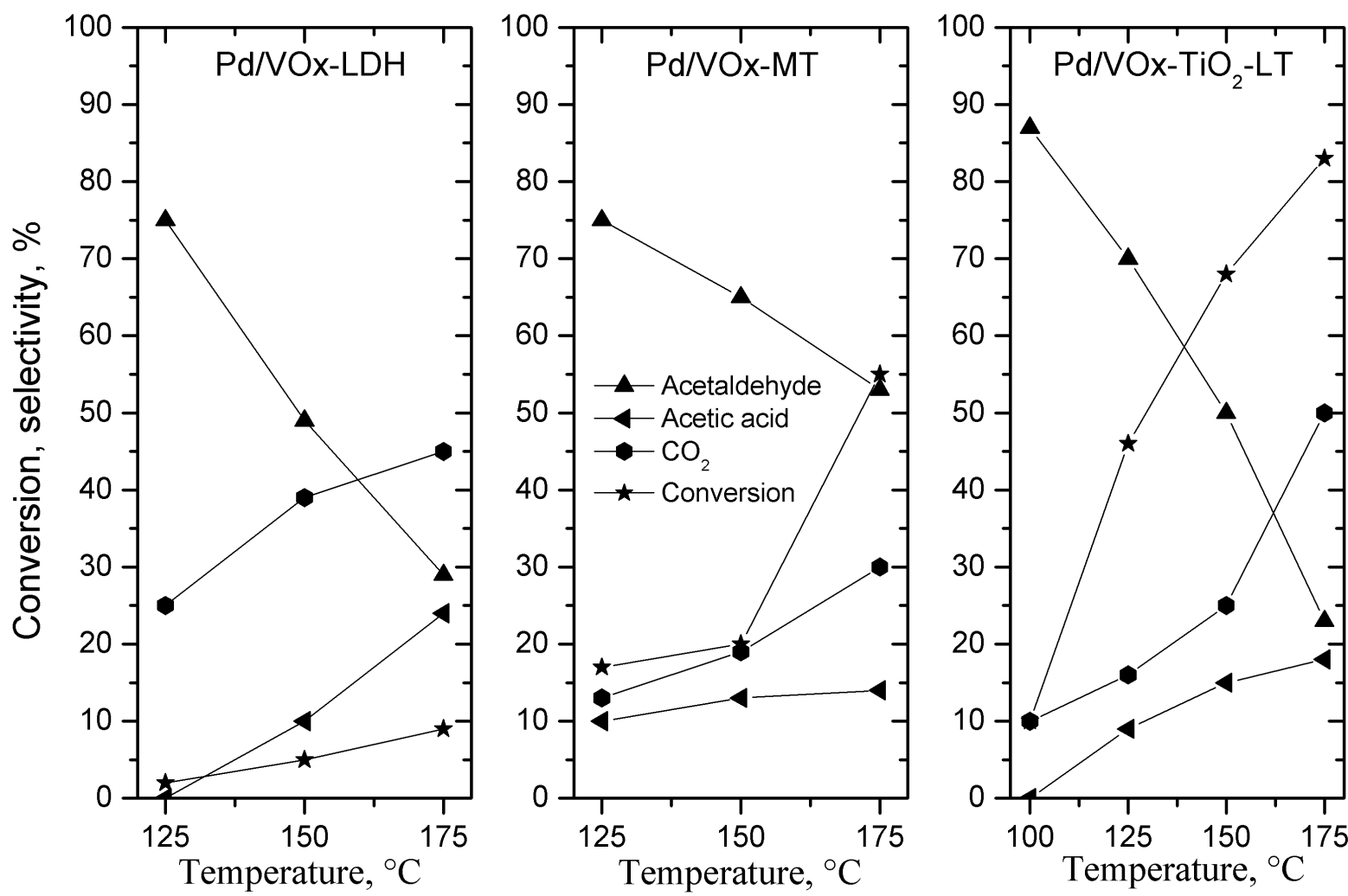

Fig. 5. Catalytic conversion of $3 \%$ ethylene/12\% oxygen $/ 24 \%$ water/He gas mixture as a function of temperature over different catalysts The measurements were carried out at atmospheric pressure, GHSV $=3600 \mathrm{~h}^{-1}$, conversions and selectivities were calculated from the ethylene consumption and on the basis of the carbon content of the products.

1. Hafner W, Jira R, Sedlmeier J, Sieber R, Rüttinger R, Kojer H (1959) Angew Chem 71:176

2. Park ED, Lee KH, Lee JS (2000) Catal Today 63:147

3. Evnin B, Rabo JA, Kasai PH (1973) J Catal 30, 109

4. Van der Heide E, Zwinkels M, Gerristen A, Scholten J (1992) Appl Cat A 86:181

5. Stobbe-Kreemers AW, Makkee M, Scholten JJF (1997) Appl Cat A 156:219

6. Park ED, Lee JS (1998) J Catal 180:123

7 Park ED, Lee JS (2000) J Catal 193:5

8. Dyakonov AJ (2003) Appl Catal B 45:257

9. Espeel PH, Tielen MC, Jacobs PA (1991) Chem Commun 10:669

10. Mitsudome T, Umetani T, Mori K, Mizugaki T, Ebitani K, Kaneda K (2006) Tetrahedron Lett 47:1425

11. Arhancet JP, Davis ME, Hanson BE (1991) Catal Lett 11:129

12. Okamoto M, Taniguchi Y (2009) J Catal 261:195

13. Frusteri F, Parmaliana A, Ostrovskii NM, Ianibello A, Giordano N (1997) Catal Lett 46:57

14. Long RQ, Yang RT (2000) J Catal 196:73

15. Węgrzyn A, Rafalska-Łasocha A, Dudek B, Dziembaj R (2006) Catal Today 116:74

16. Gao X, Wachs IE (2000) J Phys Chem B 104:1261 
17. Tian H, Ross EI, Wachs IE (2006) J Phys Chem B 110:9593

18 Labajos FM, Rives V, Ulibarri,M.A (1992) J Mater Sci 27:1546

19 Forni L, Terzoni G (1977) Ind Eng Chem Process Des Dev 16288

20 Grygar T, Čapek L, Adam J, Machovič V (2009) J Electroanal Chem 633:127

21 Gao X, Banares MA, Wachs IE (1999) J Catal 188:325

22 Pope D, Smith WL, Eastlake MJ, Moss RL (1971) J Catal 22:72

23 Smith WL (1972) J Appl Cryst 5:127 